CARACTERÍSTICAS NUTRICIONAIS E TEMPO DE PRATELEIRA DO ABACAXI

DESIDRATADO (Ananas comosus, L. Merril,Bromeliaceae) COMERCIALIZADO

EM CURITIBA-PR

\title{
CHARACTERISTICS OF CHEMICAL AND NUTRITIONAL COMPOSITION, SHELF LIFE OF DEHYDRATED PINEAPPLE (Ananas comosus, L. Merril,Bromeliaceae) SOLD IN CURITIBA, PARANÁ
}

\author{
Carem Caroline Marcello SIMON ${ }^{1}$, Carolina Muniz TRENTIN${ }^{1}$, Eric Luiz DOMINGOS ${ }^{1}$, \\ Gabriel Henrique da Silva BORSATO', María Eugenia BALBI ${ }^{2 *}$
}

1: Alunos de graduação em Farmácia, da Universidade Federal do Paraná (UFPR)

2: Mestre em Tecnologia de Alimentos, docente da disciplina de Bromatologia do Departamento de

Farmácia da Universidade Federal do Paraná (UFPR).

*: Autor para correspondência: bromatologia.ufpr@gmail.com

\section{RESUMO:}

O abacaxi desidratado (Ananas comosus L. Merril, Bromeliaceae), vem ganhando espaço graças a sua praticidade e valor nutricional, mas são poucas as pesquisas realizadas para analisar a eficiência e funcionalidade desse alimento. Com finalidade de contribuir para esses aspectos, foram realizadas análises centesimais que avaliam a composição química e nutricional. A amostra foi submetida a determinações como o teor de carboidratos, lipídios, proteínas, fibras, cinzas, umidade, acidez e pH, segundo procedimentos do IAL e AOAC, além da análise macroscópica e sensorial. As análises apresentaram resultados significantes, mostrando que possui baixo teor de lipídios $(0,20 \%)$, proteínas $(3,59 \%)$ e minerais $(1,11 \%)$, em contrapartida apresenta quantidade significativa de carboidratos $(43,90 \%)$ e umidade $(48,13 \%)$, sendo os maiores componentes da amostra. O abacaxi desidratado (A.comosus) apresentou baixo valor calórico, mas deve-se atentar pela quantidade ingerida, pois o fruto desidratado possui valores aumentados de fibras e açúcares.

Palavras-chave: Abacaxi desidratado, composição química e nutricional, lipídios, proteínas, minerais, carboidratos e umidade.

\section{ABSTRACT:}

Dehydrated pineapple, (Ananas comosus L. Merril, Bromeliaceae), is becoming famous thanks to practicality and nutritional value, however there are few researches to analyze its efficacyand functionality. In order to contribute to these aspects, proximate analyses were performed to rate pineapples chemical and nutritional composition. The sample passed by carbohydrate, protein, fibers, ashes, humidity, $\mathrm{pH}$ and acidity, according to procedures in IAL and AOAC, beyond macroscopic and sensory analysis. The results were significant, presenting low lipids $(0,20 \%)$, protein $(3,59 \%)$ and mineral $(1,11 \%)$ levels. On the other hand carbohydrate $(43,90 \%)$ and humidity $(48,13 \%)$ most comprises the sample. Dehydrated pineapple presented low caloric value, but it must attempt on ingested quantity, because dehydrated pineapple generally contains higher levels of fibers and sugar.

Keywords: Dehydratedpineapple, chemistry composition and nutritional, lipids, proteins, minerals, carbohydrates and moisture. 


\section{INTRODUÇÃO}

Típico do Brasil, o abacaxi (Ananas comosus L. Merril, Bromeliaceae) é um fruto característico de climas tropicais (úmido e quente), é originário de uma planta, monocotiledônea, herbácea e perene da família Bromeliaceae (EMBRAPA, 2005). Seu crescimento ótimo é em torno de 22 e $32^{\circ} \mathrm{C}$, razão pela qual é uma planta típica da região norte e nordeste. Seu crescimento dura em média de 12 a 24 meses, dependendo de fatores externos (CARVALHO et al, 2005). O Brasil produz cerca de 1.470.391 toneladas é de abacaxi. O estado brasileiro que possui a maior produção de Ananas comosus é a Paraíba com $17,52 \%$ seguido do Pará e da Bahia (EMBRAPA, 2005).

A composição química do abacaxi varia muito de acordo com a época em que é produzido, gerando frutos com maior teor de açúcares e menor acidez no verão. $\mathrm{O}$ abacaxi possui elevado valor energético, devido à sua alta composição de açúcares, e valor nutritivo pela presença de sais minerais e de vitaminas, principalmente ácido ascórbico, tiamina, riboflavina e niacina (LEMOS et al, 2010 apud FRANCO, 1989). Há presença da enzima bromelina, importante composto na terapêutica, que possui ações anti-inflamatórias, anticoagulantes e antiexsudadtiva, podendo apresentar efeitos de inibição da agregação plaquetária (DOMINGOS e COSTA, 2011), essa enzima também é utilizada na indústria alimentícia nos processos de clarificação de cervejas, fabricação de queijos, amaciamento de carnes, preparo de alimentos infantis e dietéticos, enriquecimento de farinhas, produção de leite de soja, entre outros. Nas indústrias têxteis para amaciamento de fibras e também na produção de detergentes (FRANÇA-SANTOS et al, 2009).

A secagem de frutas é utilizada para a conservação de alimentos, pois a água afeta de maneira decisiva o tempo de preservação dos produtos, influenciando sua qualidade e tempo de vida de prateleira (PASTRO et al, 2011 apud GRENSMITH, 1998).

O abacaxi desidratado (A. comosus), vem ganhando espaço graças a sua praticidade e valor nutricional, por ser comercializado seco possui uma concentração maior dos nutrientes e um maior tempo de prateleira. O processo de desidratação traz vantagens como a concentração de nutrientes como carboidratos, fibras, vitaminas e minerais. A fruta desidratada também tem desvantagens como a perda de componentes benéficos a saúde, um exemplo é o ácido ascórbico. Deve-se atentar ao valor calórico, que também aumenta, porém não é muito vantajoso para pessoas que visam à perda de peso.

Nos dias atuais, são poucas as pesquisas realizadas para analisar a eficiência e funcionalidade de um alimento desidratado. A literatura e a indústria não fornecem informações suficientes para nos dizer se os mesmos compostos funcionais de um 
alimento in natura continuam presentes no alimento após o processo de desidratação. Por ser um alimento desidratado, o abacaxi apresenta maior tempo de prateleira, mantendo o mesmo sabor e a alta concentração de sólidos totais e solúveis caracteriza um aumento no valor nutricional e calórico do produto. É um alimento funcional, pois apresenta maior concentração de fibras do que o in natura.

O presente estudo visa determinar a composição química e nutricional da espécie Ananas comosus (fruto desidratado), verificando as características do abacaxi desidratado como alimento funcional e estabelecendo a porção diária do alimento. Para isso, foram realizadas análises para determinar o teor de carboidratos, lipídios, proteínas, fibras, cinzas, umidade, acidez e pH, segundo procedimentos já descritos.

\section{MATERIAL E MÉTODOS}

A amostra de abacaxi desidratado por estufa foi obtida no mercado Municipal varejista na região central de Curitiba. O produto foi produzido na cidade de Fraiburgo, Santa Catarina e dispensado de Registro no Ministério da Saúde conforme resolução 23 do Ministério da Saúde (BRASIL, 2000).

\subsection{Análise Macroscópica}

Análise ótica de presença de objetos estranhos, que foram posteriormente retirados da amostra.

\subsection{Análise Sensorial}

No início e no fim das análises foram realizados testes sensoriais pelos autores, avaliando possíveis perdas da qualidade sensorial do abacaxi desidratado ( $A$. comosus) devido ao armazenamento.

\subsection{Determinação da Porção}

A separação das amostras foi feita através do quarteamento para separar em quantidades menores e obter uma amostra significativa para análise. Para separar as amostras foram utilizadas medidas caseiras padronizadas de uma rodela de abacaxi e uma xícara, que corresponde a seis rodelas, além de balança semi-analítica. As amostras foram trituradas no liquidificador para início das determinações. 


\subsubsection{Determinação da composição química e nutricional}

Foram feitas análises para determinação da composição físico-química do abacaxi desidratado, tais como:

- Determinação de Umidade:

Aumidade (U\%) foi determinada pelo método indireto (IAL, 2008).

- Determinação de Proteínas:

Foram determinadas pelo método de micro Kjeldahl (AOAC,1995), usando fator de conversão igual a 5,75, segundo a RDC 360 (BRASIL, 2003).

- Determinação de Lipídios:

As gorduras totais foram determinadas pelo método do extrato etéreo (IAL, 2008).

- Determinação de Minerais:

Para a quantificação de minerais foi utilizado o método da determinação de minerais fixo (IAL, 2008).

- Determinação de Fibras:

A determinação de fibras foi realizada segundo o método descrito na AOAC (1970).

- Determinação de Carboidratos:

A determinação de carboidratos foi realizada através do método da diferença.

Tempo de prateleira.

- Determinação de Acidez e pH:

A determinação da acidez foi realizada pelo método da acidez total titulável (IAL, 2008) e o pH foi analisado através de pHmetro.

\subsubsection{Cálculos do Valor Energético e dos Valores Diários de Referência}

Seguindo as diretrizes da RDC 360 (BRASIL, 2003).

\subsubsection{Tratamento Estatístico}

O tratamento estatístico usado foi: média simples e desvio padrão amostral.

\section{RESULTADOS E DISCUSSÃO}

O abacaxi desidratado (Ananas comosus L. Merril, Bromeliaceae) apresentou cor amarelo escura, não tendo alteração na cor durante todo o período do estudo, e odor característico de abacaxi. O produto tem forma de rodelas, sem o eixo central, e aparente rugosidade, devido à desidratação. 
Após análise macroscópica a porção triturada foi armazenada em recipiente plástico, a temperatura ambiente e armazenado em local sem iluminação.

A análise sensorial inicial nos mostrou, ao mastigar, um produto de aspecto borrachudo, com sabor característico ao do abacaxi in natura. Após um tempo, o abacaxi desidratado apresentou melhora na mastigação, isso se dá pela reidratação que ocorreu na boca durante o processo mecânico da digestão. No fim do experimento, o produto ainda apresentava aspecto borrachudo, mas o sabor e odor diferenciaram. Na tabela 1 são apresentados os valores obtidos pelas análises químicas e nutricionais do abacaxi desidratado.

Os valores são apresentados em porcentagem, com o respectivo tratamento estatístico.

TABELA 1: Composição química e nutricional do abacaxi desidratado (Ananascomosus, L. Merril, Bromeliaceae) em 100g

\begin{tabular}{lrl}
\hline Determinação & \multicolumn{1}{c}{$\mathbf{1 0 0 g}$} \\
\hline Umidade & $48,13 \%$ & 2,21 \\
Proteínas* & $3,07 \%$ & 0,04 \\
Carboidratos & $43,90 \%$ & 3,47 \\
Lipídios & $0,20 \%$ & 0,02 \\
Fibras & $3,59 \%$ & 0,10 \\
Minerais & $1,11 \%$ & 0,07 \\
Kcal & 189,68 \\
\hline
\end{tabular}

* utilizou-se fator de conversão para proteína de 5,75 segundo a RDC 360 (BRASIL, 2003)

A média dos teores de umidade (U\%) foi de $48,13 \% \pm 2,21$. A amostra mesmo sendo desidratada apresentou um valor alto de umidade, que difere da literatura. Diferença que pode ser devido ao processo de desidratação utilizado pela indústria (estufa), por erros experimentais na determinação de umidade, ou até pelo modo como é comercializado. O abacaxi desidratado sai de fábrica embalado a vácuo em porções de $1 \mathrm{~kg}$, para fins de praticidade os comerciantes separaram em pacotes plásticos com porções menores.

Outros estudos citaram valores de umidade de $20 \%$ para abacaxi desidratado, porém o produto foi submetido a 56 horas de tratamento em estufa e desidratação osmótica, o que influencia consideravelmente na quantidade de água presente no alimento. (GONÇALVES et al., 2009)

Em análise de abacaxi desidratado para avaliação de modelos de secagem e avaliação na qualidade da embalagem os valores de umidade variam em torno de 20 a $25 \%$, sendo também desidratado em fatias e armazenado a temperatura 
ambiente. (QUINTERO, 2007)

Para proteínas, não foram encontrados valores de referência, para o abacaxi desidratado. Analiticamente, obteve-se um teor médio de 3,07\% $\pm 0,04$, diferente do resultado obtido por Oliveira et al (2012) $(2,20 \pm 0,49)$, que estudou as estruturas do abacaxi in natura. O resultado obtido foi próximo ao encontrado por Pastro et al (2011) $\left(2,98 \%\right.$, secando a $50^{\circ} \mathrm{C}$ e $3,07 \%$, secando a $\left.60^{\circ} \mathrm{C}\right)$. Essa diferença pode ser vista pela variedade do abacaxi ou pelo acréscimo de aditivos alimentares. O teor de proteínas aumenta significativamente em produtos desidratados, isso é dado pela diminuição nos teores de umidade, promovendo uma concentração de solutos de modo que estes componentes estão presentes em maiores quantidades no abacaxi desidratado com relação ao in natura (PASTRO et al, 2011).

Para carboidratos encontrou-se um valor médio de 43,90\%, diferente do valor encontrado no rótulo do produto (aproximadamente $72,7 \%$ ), essa diferença se da principalmente pela reidratação do produto durante o armazenamento, dessa forma dissolvendo os açúcares e por consequência diminuindo a quantidade detectada. Pode-se também comparar o valor obtido aos valores encontrados para carboidratos da fruta in natura, que foram de 13,53\% (BORTOLATTO \& LORA, 2008), o valor é menor justamente devido a maior parcela de água presente na fruta in natura, dessa forma os sólidos solúveis (carboidratos) apresentam-se mais diluídos e dessa forma contribuindo de uma forma mais suave ao todo em termos de porcentagem.

O valor médio encontrado para lipídios foi de $0,20 \% \pm 0,02$. Valor igual ao encontrado por Oliveira et al (2012), em estudo com abacaxi in natura. Isso mostra que a desidratação não alterou a concentração de gorduras totais (lipídios) em relação à fruta in natura.

A porcentagem média de fibras foi de $3,59 \%( \pm 0,10)$. Devido à dificuldade de se encontrar literatura contendo valores de fibras para o abacaxi desidratado, o resultado obtido foi comparado ao o valor presente no abacaxi in natura, que é de $0,6 \%$ (BORTOLATTO \& LORA, 2008). Pode-se afirmar que essa alteração é proveniente da diferença do teor de umidade da fruta in natura quando comparada a desidratada, de forma que quanto maior teor de umidade há maior tendência das fibras estarem solubilizadas, portanto representa uma menor porcentagem no todo, comportamento esse que pode ser observado em todos os componentes do abacaxi. Já no abacaxi desidratado, por teor de umidade reduzido, as fibras se encontram mais concentradas.

Foi encontrado o valor médio de $1,11 \% \pm 0,07$ para minerais, resultado diferente do encontrado por Lemos et al (2010) (2,00\%) em seu estudo com abacaxi desidratado. Os teores de cinzas variam em função da localidade onde a variedade fo plantada e da composição do solo onde crescem (LEMOS et al, 2010 apud BORTOLATTO \& LORA, 2008). Isso explica a diferença significativa de $100 \%$ no resultado.

$\mathrm{Na}$ tabela 2 encontram-se os valores obtidos para a acidez e $\mathrm{pH}$ do abacaxi desidratado em 7 (sete) dias de semanas diferentes. Os valores encontradosi apresentaram uma significativa diferença aos valores $(1,78)$ obtidos por Quintero (2007) em estudo realizado com abacaxi desidratado. Essa diferença pode ter ocorrido devido à temperatura ambiente em que as amostras foram submetidas, ao aumento da umidade no transcorrer dos estudos e principalmente ao método de armazenamento, o 
qual foi mantido em recipientes plásticos desde a sua saída do varejo o que não seria a maneira mais adequada de reserva-lo. Os valores encontrados para $\mathrm{pH}$ foram próximos ao encontrado por Quintero (2007) e Lemos et al (2010) para o abacaxi desidratado.

TABELA 2: Acidez e valores de $\mathrm{pH}$ do abacaxi desidratado (Ananascomosus, L. Merril, Bromeliaceae), durante tempo de conservação.

\begin{tabular}{cccc}
\hline Dias & Média da acidez (\%) & Desvio padrão & pH \\
\hline 1 & 4,44 & 0,15 & 3,98 \\
2 & 4,62 & 0,04 & 4,01 \\
3 & 4,15 & 0,05 & 3,97 \\
4 & 3,09 & 0,06 & 3,81 \\
5 & 4,29 & 0,04 & 3,86 \\
6 & 4,55 & 0,23 & 3,80 \\
7 & 3,82 & 0,01 & 3,81 \\
\hline
\end{tabular}

Conforme ilustrado na Tabela 2, o pH das amostras de abacaxi desidratado tiveram um $\mathrm{pH}$ relativamente constante e sem uma diferença significativa entre eles. Nos últimos dias do estudo as amostras obtiveram um $\mathrm{pH}$ menor do que nas primeiras semanas da análise, o que pode ser um fator desfavorável ao alimento uma vez que com o abaixamento do $\mathrm{pH}$, o abacaxi apresentará um teor ácido elevado, diferindo então na sua palatabilidade. Isso é extremamente relevante quando consideramos o tempo que o alimento pode permanecer em prateleira, pois essa redução de pH pode favorecer a degradação do produto.

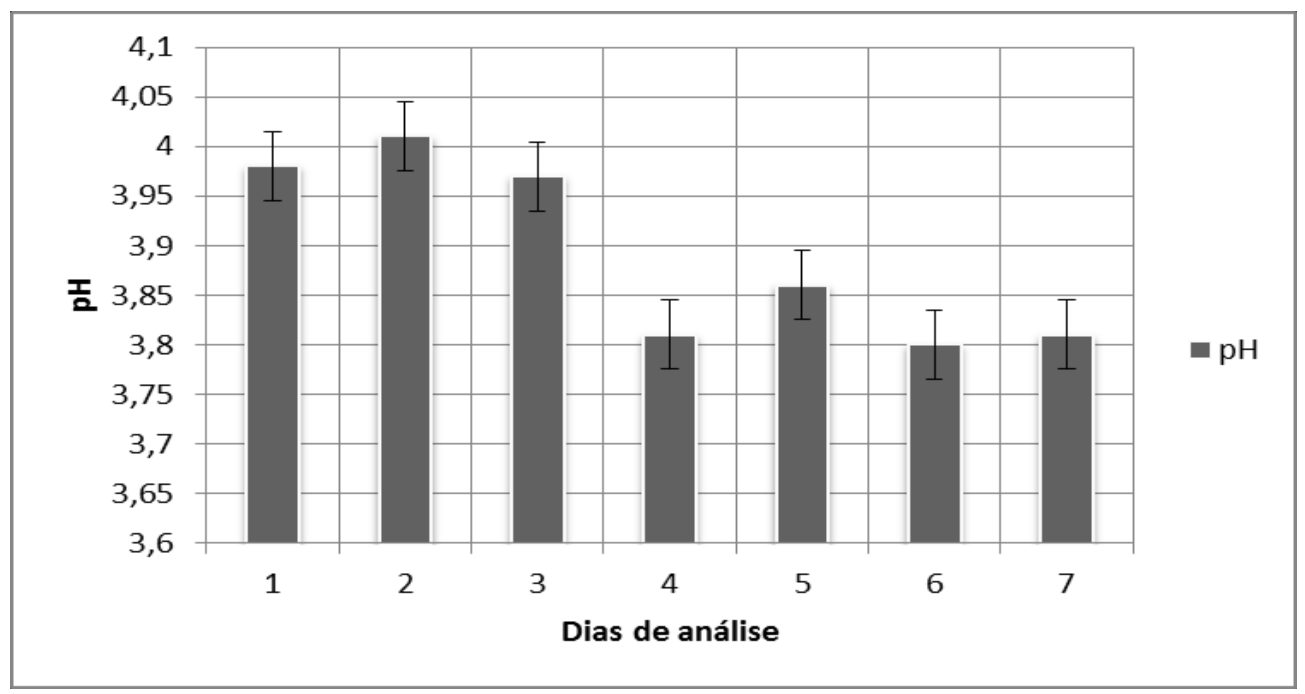

FIGURA 1: Gráfico para análise do pH em diferentes dias durante a análise do abacaxi desidratado (Ananas comosus, L. Merril, Bromeliaceae)

Analisando as tabelas 3 e 4, observou-se uma diferença significativa nos valores de carboidratos e fibras. Observou-se também que o valor energético apresentado 
encontrado por Quintero (2007) e Lemos et al (2010) para o abacaxi desidratado.

TABELA 3: $\mathrm{pH}$ em diferentes dias durante a análise do abacaxi desidratado (Ananascomosus, L. Merril, Bromeliaceae)

\begin{tabular}{c|c}
\hline Dias & pH \\
\hline 1 & 3,98 \\
2 & 4,01 \\
3 & 3,97 \\
4 & 3,81 \\
5 & 3,86 \\
6 & 3,80 \\
7 & 3,81 \\
\hline
\end{tabular}

Conforme ilustrado na figura $2, \mathrm{o} \mathrm{pH}$ das amostras de abacaxi desidratado tiveram um $\mathrm{pH}$ relativamente constante e sem uma diferença significativa entre eles. Nos últimos dias do estudo as amostras obtiveram um $\mathrm{pH}$ menor do que nas primeiras semanas da análise, o que pode ser um fator desfavorável ao alimento uma vez que com o abaixamento do $\mathrm{pH}$, o abacaxi apresentará um teor ácido elevadodiferindo então na sua palatabilidade. Isso é extremamente relevante quando consideramos o tempo que o alimento pode permanecer em prateleira, pois essa redução de $\mathrm{pH}$ pode favorecer a degradação do produto.

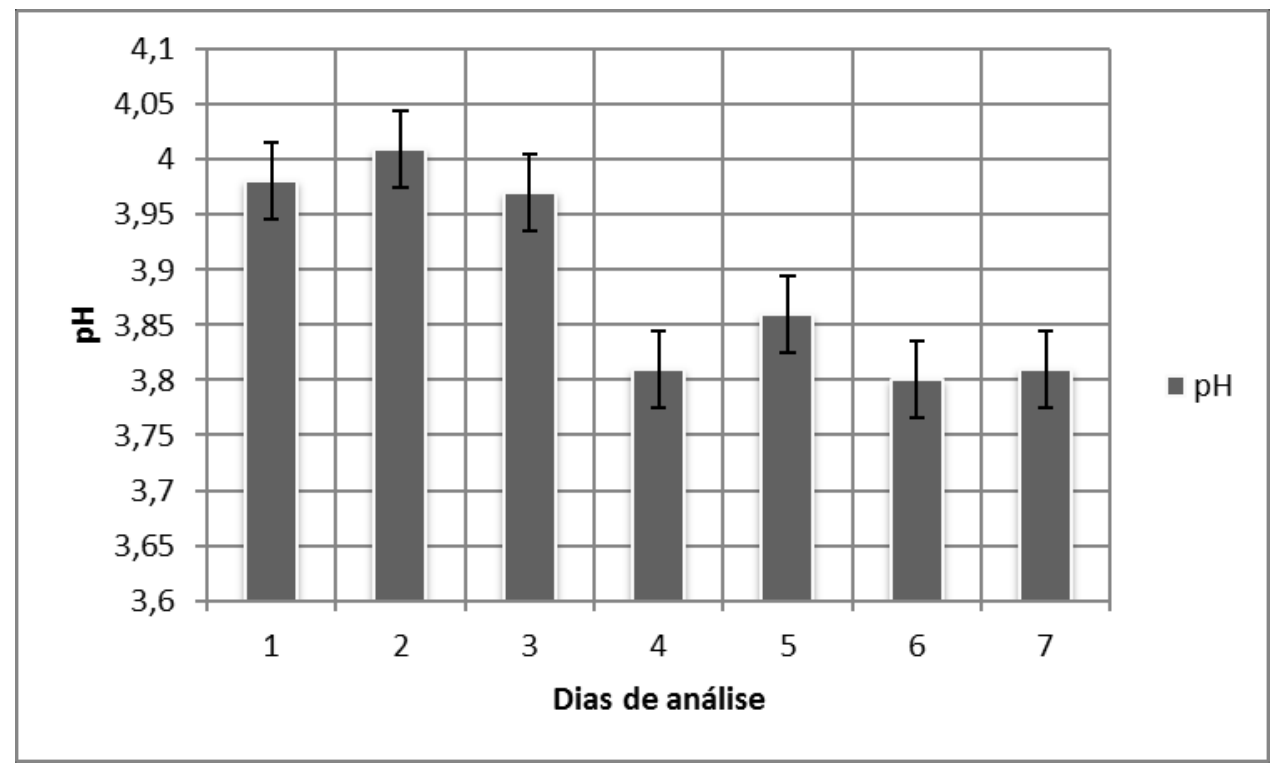

FIGURA 2: Gráfico para análise do pHem diferentes dias durante a análise do abacaxi desidratado (Ananas comosus, L. Merril, Bromeliaceae) 
Analisando as tabelas 4 e 5 e comparando com a figura 3, observou-se uma diferença significativa nos valores de carboidratos e fibras. Observou-se também que o valor energético apresentado no rótulo do produto não condiz com a quantidade de no rótulo do produto não condiz com a quantidade de carboidratos e proteínas do abacaxi desidratado. Essas diferenças podem ser justificadas pela diferença de metodologia utilizada no controle de qualidade da empresa e nos erros experimentais durante este estudo.

TABELA 3: Informação nutricional do abacaxi desidratado (Ananas comosus, L. Merril, Bromeliaceae) na porção de $12 \mathrm{~g}$ utilizando uma rodela como medida caseira.

\begin{tabular}{ccc}
\hline Informação & Quantidade na porção & $\%^{\text {VD* }}$ \\
\hline Valor energético & $22,72 \mathrm{Kcal}=94,9 \mathrm{~kJ}$ & 1,06 \\
Carboidratos & $5,26 \mathrm{~g}$ & 1,70 \\
Proteínas & $0,36 \mathrm{~g}$ & 0,54 \\
Lipídios & $0,02 \mathrm{~g}$ & 0,04 \\
Fibras & $0,42 \mathrm{~g}$ & 1,68 \\
\hline
\end{tabular}

*VD\% segundo RDC 360 (BRASIL, 2003)

TABELA 4: Informação nutricional do abacaxi desidratado (Ananas comosus, L. Merril, Bromeliaceae) na porção de $50 \mathrm{~g}$ utilizando uma xícara de chá como medida caseira.

\begin{tabular}{ccc}
\hline Informação & Quantidade na porção & $\%$ VD* \\
\hline Valor energético & $94,84 \mathrm{Kcal}=398 \mathrm{~kJ}$ & 4,74 \\
Carboidratos & $21,95 \mathrm{~g}$ & 7,31 \\
Proteínas & $1,51 \mathrm{~g}$ & 2,01 \\
Lipídios & $0,08 \mathrm{~g}$ & 0,14 \\
Fibras & $1,77 \mathrm{~g}$ & 7,08 \\
\hline
\end{tabular}

*VD\% segundo RDC 360 (BRASIL, 2003)

A tabela 5 mostra os resultados da Informação Nutricional do abacaxi desidratado, na porção de $50 \mathrm{~g}$, segundo recomendação do fabricante. As percentagens dos Valores Diários (VD\%) foram obtidas segundo a RDC 360 (BRASIL, 2003) 
TABELA 5: Informação Nutricional contida no rótulo da embalagem do produto

\begin{tabular}{lc|c}
\hline \multicolumn{2}{c}{ Informação Nutricional Porção de $\mathbf{5 0 g}$ (8 colheres de sopa) } \\
\hline \multicolumn{2}{c}{ Quantidade por porção } & $\%$ VD ( $)$ \\
\hline Valor Energético & $75 \mathrm{Kcal}=317 \mathrm{KJ}$ & $3,80 \%$ \\
Carboidratos & $43 \mathrm{~g}$ & $14,30 \%$ \\
Proteínas & $1,7 \mathrm{~g}$ & $2,30 \%$ \\
Gorduras totais & $0 \mathrm{~g}$ & 0 \\
Gorduras saturadas & $0 \mathrm{~g}$ & 0 \\
Gorduras trans & $0 \mathrm{~g}$ & $* *$ \\
Fibra alimentar & $3 \mathrm{~g}$ & $12 \%$ \\
Sódio & $0 \mathrm{mg}$ & 0 \\
\hline
\end{tabular}

*\% Valores Diários com base em uma dieta de $2.000 \mathrm{Kcal}$ ou $8400 \mathrm{KJ}$.

Seus valores diários podem ser maiores ou menores dependendo de suas necessidades energéticas.

** VD não estabelecido

\section{CONCLUSÃO}

O estudo e a caracterização do abacaxi desidratado (Ananas comosus, L.Merril, Bromeliaceae) permitiram a avaliação das características de composição química e nutricional e comparação com os valores da literatura. Os resultados apresentam alguns valores iguais e/ou semelhantes ou que diferem da literatura pesquisada e da tabela funcional presente no rótulo da embalagem do abacaxi desidratado.

No decorrer deste estudo observou-se a importância do correto controle de qualidade e armazenamento do abacaxi desidratado, desde a indústria até o varejista.

O abacaxi desidratado é um excelente alimento funcional, possuindo baixas calorias, mas seu valor comercial é um pouco elevado e nem todos tem acesso a esse produto. Sugere-se que sejam realizados projetos em que o abacaxi seja vendido a um preço mais acessível, mantendo a mesma qualidade.

\section{REFERÊNCIAS}

AOAC. ASSOCIATION OF OFFICIAL AGRICULTURAL CHEMISTS. OfficialMethodsofAnalysis. USA: AssociationofOfficialAgriculturalChemists, Washington D.C. 1995.

AOAC. ASSOCIATION OF OFFICIALAGRICULTURAL CHEMISTS. Official Methods of 
Analysis. 12th ed. USA: Association of Official Agricultural Chemists, Washington D.C. 1970. $1094 \mathrm{p}$.

BORTOLATTO, J.; LORA, J. Avaliação da composição centesimal do abacaxi (Ananas comosus (L.) Merril) liofilizado e in natura. 2008. Disponível em: <http://periodicos.unesc.net/index.php/saude/article/viewArticle/142>. Acesso em: $13 / 05 / 2014$.

BRASIL. ANVISA-Agência Nacional de Vigilância Sanitária. Resolução n 23, de 15 de março de 2000. O Manual de Procedimentos Básicos para Registro e Dispensa da Obrigatoriedade de Registro de Produtos Pertinentes à Área de Alimentos. Diário Oficial [da união], Brasília, 16 mar. 2000. Disponível em: <http://www.abic.com.br/publique/media/CONS_leg_resolucao23-00.pdf>. Acesso em: 10/05/2014.

BRASIL. ANVISA - Agência Nacional de Vigilância Sanitária. Resolução RDC n³60, de 23 de dezembro de 2003. Regulamento Técnico sobre Rotulagem Nutricional de

Alimentos Embalados, tornando obrigatória a rotulagem nutricional. Diário Oficial [da união], Brasília, 26 dez. 2003. Disponível em: <http://www.crn3.org.br/legislacao/doc/ RDC_N_360_DE_23_DE_DEZEMBRO_DE_2003.pdf>. Acesso em 10/03/2014.

CARVALHO, S. L. C. de; NEVES, C. S. V. J; BÜRKLE, R.; MARUR, C. J. Épocas de indução floral e soma térmica do período do florescimento à colheita de abacaxi 'smoothcayenne'. Revista Brasileira de Fruticultura. Jaboticabal, v. 27, n. 3, p. 430-433, dezembro, 2005. Disponível em: <http://www.scielo.br/pdf/rbf/v27n3/27790.pdf>. Acesso em: 13/03/2014.

DOMINGOS, T.; COSTA, L. Bromelina 3000. Viafarma. Ipiranga, 2011. Disponível em: <http://www.viafarmanet.com.br/site/downloads/literatura/BROMELINA\%203000.pdf> . Acesso em: 11/03/2014.

EMBRAPA. Cultivo do abacaxi em Rondônia, 2005. Disponível em: <http://sistemasdeproducao.cnptia.embrapa.br/FontesHTML/Abacaxi/CultivodoAbac axiRO/index.htm.>. Acesso em: 22/03/2014.

FRANÇA-SANTOS, A.; ALVES, R. S.; LEITE, N. S.; FERNANDES, R. P. M. Estudos bioquímicos da enzima bromelina do Ananas comosus (abacaxi). Scientia Plena. São Cristóvão, v. 5, n. 11, p. 1-6, 2009. Disponível em: <http://www.scientiaplena.org.br/ index.php/sp/article/view/749/402>. Acesso em: 20/03/2014. 
FRANCO, G. Tabela de composição química dos alimentos. 8 ed. Rio de Janeiro: Livraria Atheneu, 1989.230p.

GONÇALVES, S.S., ANDRADE, J.S., SOUZA, R.S. Efeito da adição de ácidos ascórbico e cítrico nas características do abacaxi desidratado obtido da cultivar "pérola" proveniente de novo remanso, Amazonas, Brasil. Ciências Agrárias. Universidade Federal do Amazonas. 61 ${ }^{\text {a }}$ Reunião Anual da SBPC. '20_-. Disponível em:<http://www.sbpcnet.org.br/livro/61ra/resumos/resumos/4761.htm>. Acesso em: 09/05/2014.

GREENSMITH, M. Practicaldehydration. 2ed. Flórida: CRC Press, 1998.274p.

IAL. Instituto Adolfo Lutz. Normas analíticas do Instituto Adolfo Lutz: métodos químicos e físicos para análise de alimentos. São Paulo: Instituto Adolfo Lutz 2008. 1020p.

LEMOS, D. M.; OLIVEIRA, E. N. A. de; SANTOS, D. C.; SOUSA, E. P. de; MATIAS, M. L.

Composição físico-química de resíduos de abacaxi in natura e desidratado. Tecnologia \& Ciência Agropecuária. João Pessoa, v. 4, n. 2, p. 53-56, jun. 2010. Disponível em: < http://www.emepa.org.br/revista/volumes/tca_v4_n2_jun/tca10_composicao.pdf>. Acesso em: 19/03/2014.

OLIVEIRA, J. A. R. de; CARVALHO, A. V.; MARTINS, L. H. S.; MOREIRA, D. K. T. Elaboração e caracterização físico-quimica e sensorial de estruturados de polpa concentrada de abacaxi. Revista de Alimentos Nutricionais. Araraquara, v. 23, n. 1, p. 23-31, jan./mar. 2012 . Disponível e m: < ht tp: / s e rvbib.fcfar.unesp.br/seer/index.php/alimentos/article/viewFile/1440/1201>. Acesso em: 19/03/2014.

PASTRO, D. C.; SILVA, F. S. da; SANDRI, D. O.; PORTO, A. G.Influência da temperatura de secagem nas características físico-químicas do abacaxi cultivar pérola. Congresso de Iniciação Científica. Cáceres, v. 7, out. 2011. Disponível em: < h t t p://si e c. un e mat.br/a n a i s/con i c/impress a o-

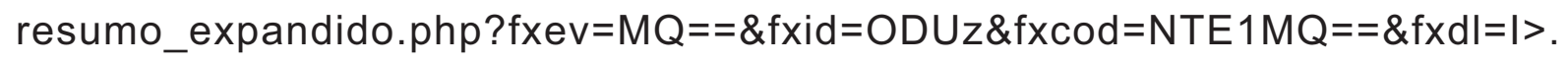
Acesso em: 05/05/2014.

QUINTERO, A.C.F. Desidratação do abacaxi: modelos de secagem, avaliação de qualidade no efeito da embalagem. Programa de Pós-Graduação em Ciência e Tecnologia de Alimentos. Viçosa, MG, 2007 . Disponível em:<http://www.tede.ufv.br/tedesimplificado/tde_arquivos/39/TDE-2008-0227T112813Z-1010/Publico/texto\%20completo.pdf>. Acesso em: 09/05/2012. 